\title{
Promoting Mindfulness Through Contemplative Education
}

\author{
Sepideh Mahani, Higher Colleges of Technology, United Arab Emirates
}

\begin{abstract}
For years, higher education institutions in the United States have developed courses in the field of liberal education that focus on social, political, economic and environmental issues with a global outlook. As such, students are taught critical thinking, critical reasoning, and critical writing skills. While students learn to engage in debates, decisive speaking, and critical analysis, they are rarely taught to feel compassionate toward these issues. Hence, in the current global community in which many countries are at war, or are facing poverty and financial crises, it is essential that higher education institutions prepare knowledgeable citizens that not only ascertain critical assessment and judgment skills, but also ascertain the art of contemplation.
\end{abstract}

This article reviews literature from various disciplines and suggests that higher education institutions must work toward integrating contemplative education and mindfulness in their curriculum in order to enhance students' learning and understanding through contemplation and personal insight. Furthermore, it is essential that higher education institutions implement multidimensional educational strategies that encourage a vigorous and universal understanding of cross-cultural communication. Additionally, this paper examines the role of elements, such as experience, contemplations, and transformation, in teaching and preparing future graduates for the current global community. Furthermore, it evaluates strategies that can be used by higher education leaders in creating multidimensional and effective learning environments.

Keywords: Contemplative Education; Mindfulness; Transformational Learning; Higher Education

\section{INTRODUCTION}

n order to meet the needs of the changing global community, higher education institutions must ensure
that students graduate with the knowledge and skills that are required to have an active role in the global
society. It is important that higher education institutions implement multidimensional educational

\section{INTEGRATED LEARNING}

Throughout the history of higher education in the United States, institutions have experienced both transformation and continuity. While some disciplines have evolved by creating new paths to knowledge and understanding of the world, other disciplines have preserved their traditional practices. However, integrated learning is a practice that dates back to the foundation year of higher education system in the United States (Palmer \& Zajonc, 2010). Palmer and Zajonc (2010) defined integrated learning as a connection of knowledge and expertise from different fields of education where students are encouraged to make connections across different disciplines. In Europe, integrated learning dates back to the $12^{\text {th }}$ century, during which the goal of cathedral schools was to create strong knowledgeable men through integration of the Seven Liberal Arts (Palmer \& Zajonc, 2010). The Seven Liberal Arts were divided into two sections called the Trivium and the Quadivium. While the Trivium consisted of courses in grammar, rhetoric and logic, the Quadrivium contained courses in arithmetic, geometry, harmonics, and astronomy (M. Taylor, 2007). As the foundation of the Several Liberal Arts - the integration of Trivium and Quadrivium interspersed in order to produce - educated the author. It was believed that these subjects created a path that would take students through a religious journey to bring them closer to God (Palmer \& Zajonc, 2010). Today, 
while majority of higher education institutions have distanced themselves from teaching religious ideologies in the classroom and have become more secular, and the field of liberal education still remains a junction where many disciplines meet and integrate. However, over the past decade, there has been a significant rise in integrated and interdisciplinary teaching in higher education institutions in the United States. Interdisciplinary programs promote interaction and collaborative work between different fields that historically have been divided or operate in isolation (Palmer \& Zajonc, 2010; William, 2011). Colleges and universities in the United States are continuously encouraged to provide students with interdisciplinary and multidimensional education. As a result, the United States' federal funding agencies give priority and funding to research projects and programs which mainly follow an interdisciplinary approach in order to prepare future graduates with multidimensional education (Holey, 2009).

\section{EXPERIENTIAL LEARNING}

One approach to ensure students are provided with a multidimensional education is to encourage experiential learning. Kolb (1984) suggested that experiential learning theory provides a completely different outlook on how learning is acquired; in particular, it provides a complete amalgamated perception on learning that joins experience, insight, reasoning, and behavior. The term experiential was given to the theory since it connects the works of theorists, such as Piaget, Dewey, and Lewin, as well as it focuses on experience as a significant element in the learning process. Other learning theories, such as rationalist, behaviorists, and cognitive, focus on the role of attainment and conversion in the learning process and reject the idea that consciousness and individual learning play a significant role in the learning process (Kolb, 1984).

Kolb (1984) believed that experiential learning was a result of earlier theoretical models by the theorists Dewey, Piaget and Lewin. The three theories included the Lewinian model of action research and laboratory training, Dewey's model of learning, and Piaget's model of learning and cognitive development. The Lewinian model of action research and laboratory training suggests that the process of learning occurs through a unified process that begins with a here-and-now experience, followed by data compilation and reflection about the experience by an individual. The data is then mentally examined by the individual who then makes a decision to modify his or her behavior, hence generating new experiences. The Lewinian model is based on a four-stage cycle that includes concrete experiences, observation and reflection, formation of abstract concept and generalization, testing implication of concept in new situations, and further creating new experiences. As a result, it is through these four stages that learning occurs, and it can be unsuccessful if there is disparity between observation and action (Kolb, 1984).

Dewey's model of learning shares several similarities with the Lewinian model. For example, both stress on the importance of learning as an interactive process, which combines experiences and notions with reflection and action. According to Dewey (1938), the process of learning occurs in three stages. First, the learner observes the surrounding situation, followed by an evaluation of previous knowledge and information that the learner had acquired in previous similar experiences, and finally making a judgment based on the combination of the new information that was observed and the recollections from past experiences.

The third learning model is Piaget's model of learning and cognitive development. According to Piaget (1970), learning occurs during four stages of life. Piaget (1970) believed that the development rates of children are different for each of these periods. While intellectual growth remains constant, the intellectual functions are different depending on the different periods of an individual's life. Each period continues and does not end suddenly, and is likely to fade before the next period begins. The first period of learning is called sensory-motor and occurs at infancy, from birth to the age of 2. During this period, a child observes and learns about his or her surrounding and relations. In this stage, the child learns and practices essential actions and mechanical abilities, such as holding an object and recognizing symbols. The second stage is the preoperational period which occurs during the ages of 2 to 6. During this period, a child learns language and begins to understand the world, albeit with a very limited logic and sophistication. Unlike adults, a child is very self-absorbed in the second stage of his or her life and learns continuously, through testing, the reality, such as burning sensation after touching a hot object. The third stage occurs between the ages of seven and 14 and is referred to as the concrete stage. It is during this stage that the child learns through logic and becomes less self-centered and more independent from his experimental surroundings. The final stage of the formal operational stage begins from the age of 12 and ends by the age 15. During this stage, the 
adolescent can think more logically; therefore, he or she can articulate and assume a hypothesis without actually positioning and testing the object or the situation. During this stage, the adolescent also learns to think and plan ahead and realizes that thinking can generate several potential results (Kolb, 1984; Piaget, 1970; Wanket \& Oreovicz, 1992). Therefore, experiential learning provides educators with a different understanding and outlook on how learning is acquired, making this theory a compilation of the works of the above theories by Dewey, Piaget and Lewin. Educators must recognize that learning is a transformative process that is uninterruptedly being produced and re-produced (Kolb, 1984).

In today's educational context, educators must recognize the importance of experiential learning theories in order to provide learners with educational opportunities that would allow them to combine their existing knowledge and experience with their newly acquired knowledge. According to Sibthorp, Schumann, Gookin, Baynes, Paisley, and Rathunde (2011), since experiential learning encourages lifelong learning, it promotes multidimensional learning. Over the years, generating life-long learners has become the objective of many higher education institutions and educators. According to Rathunde (2009), experiential learners regularly demonstrate the ability to combine their experiences and learning in methods which are both objective-orientated and gratifying. It has been demonstrated that students who are experiential learners are often more motivated to learn. They often look back at their previous experiences in order to become motivated to learn and pursue a specific goal (Rathunde, 2009; Sanson, 2009; Sibthorp et al., 2011).

Given that experience plays a vital role in how learners assimilate and acquire new knowledge, it is essential for educators to embrace this element when educating students and preparing them to become valuable members of society. According to Dolan (2011), experiential learning is a spiritual process in which learning is stimulated through previous knowledge. As such, learners are encouraged to lessen their fear and anxiety of the unknown. This process is imperative for the purpose of learning to participate in the global community as it softens learners' egos and encourages them to become familiar with the unknown. Consequently, in the path to creating knowledgeable citizens, higher education institutions and educators must acknowledge the importance of wakening students' experiences by providing them with opportunities where they are encouraged to place their personal experiences into a broader context and engage in discussions with other learners. Through these activities, learners are encouraged to embrace and involve their own experiences while trying to recognize and learn about global issues (Dolan, 2011).

\section{CONTEMPLATIVE LEARNING}

Contemplation is an important element that students must learn in order to become knowledgeable global citizens. Education has helped learners acquire knowledge and has encouraged them to live their best life. However, education should also focus on educating students to feel compassion for the problems that exist in their world. In order for higher education institutions to educate and produce knowledgeable citizens, they must concentrate on teaching the art of contemplation and encourage students to understand and sense the current problems in the world. According to Zajonc (2006), contemplative practices have been used in Asian higher education for many years. In North America, however, only recently have community colleges and universities started to incorporate contemplative practices in their curricula and classroom activities. Zajonc (2006) indicated that the usage of contemplative practices in the classroom is not merely enough, hence institutions require a pedagogy that concentrates on the contemplative and ethical minds of their students and contemplative ideologies must be incorporated in institutional context.

In higher education institutions in the United States, students are taught critical thinking, reasoning, and critical writing. Students are educated to learn debates, decisive speaking, and analyzing; yet, students rarely are taught to be compassionate (Zajonc, 2006). In the current global climate where many countries are facing social, political, environmental, and economical crises, it is essential that institutions take responsibility to teach students, not just critical assessment and judgment, but also the art of contemplation where students learn to develop emotions and even think with their hearts. Zajonc (2006) stated that while many higher education institutions give great attention to social, political, economic, and environmental issues in the world, still many institutions need to incorporate these elements into their curriculum. Educating students about issues, such as poverty alone, is not enough. Institutions should also teach students how to feel compassion for these issues. 
Educators must teach students contemplation through various activities that promote observation and consideration of an issue. According to Zajonc (2006), there are six stages that one must follow while pursuing contemplative practice: 1) respect, 2) gentleness, 3) intimacy, 4) participation, 5) vulnerability, and 6) transformation. Through the first stage, individuals are encouraged to respect the opinions and beliefs of others through compassion and reverence for the other's outlook on issues. The second stage is gentleness, where individuals are encouraged to approach their subject with gentleness and calmness in order to avoid distortion. Another stage toward contemplative practice is intimacy. Zajonc (2006) suggested that while science detaches itself from its subject, contemplative inquiry moves toward becoming intimate with its subject. Participation, vulnerability, and transformation are the other three stages in contemplative inquiry. Through participation, the inquirer approaches its subject closely and participates in the experiences of its subject, yet remains secure enough to be vulnerable. Vulnerability is when the inquirer is confident enough that the phenomenon of ambiguity does not scare him, and it is in this stage that the inquirer can reach a resolution. Therefore, the stages of participation and vulnerability lead to the final stage of transformation where the inquirer becomes fully aware of its subject and reaches the objective of contemplation. This contemplative practice is what some philosophies and religions seek to achieve. The definitive practice in contemplative inquiry is when we consider, examine, and become aware of what the subject is experiencing. In Buddhism, this is referred to direct perception and Greeks refer to it as episteme or dianoia (Zajonc, 2006).

Zajonc (2006) stated that in our society, education is perceived as a tool for success and wealth. Instead, education should be about growth, revolution, and encouragement. Zajonc (2006) explains that in a class called Eros and Insight, which was taught at the Amherst College, a class of 35 students was given readings and asked to live what they read. For example, if students read a paper about being in a forest or the woods, they were encouraged to practice what they read and actually step into the woods and then inscribe what they observed, felt, and experienced. Students were encouraged to remain open to their surroundings, since in contemplative inquiry one moves from congested attention to a more receptive attention. Through various readings and poetry about love, openness, contradiction, and attention, students were taught self-love and love for others. In the final assignment of the course, students were asked to re-think the education they were seeking and write whether there should be a link between love and knowledge.

\section{TRANSFORMATIONAL LEARNING}

One of the other significant elements in educating and producing well-informed citizens is through transformative learning. According to Mezirow (1991), the transformative learning theory is the development of perspective within an individual. Throughout their lives, learners have acquired a set of experiences and knowledge, and these experiences, standards, emotions, and morals, act as structures of references that explain their world. Consequently, these structures of references act as frameworks through which they comprehend their experiences. Through these frameworks, learners accept or decline ideas that do not comply with their preconceptions. If the new idea fits their preconceived knowledge, it is therefore considered relevant information; however, if the idea goes against their preconceived awareness, it is recognized as irrelevant and insignificant. Therefore, transformative learners often move toward structures of references that are more in line with their pre-existing knowledge and their personal experiences (Mezirow, 1991). According to Mezirow (1991), learners' structures of references are divided into three components - mental, impulsive and emotional - and these are divided into two elements - habits of intellect and personal outlook. Habits of intellect are the comprehensive and customary ways of thinking and feeling prejudiced by a group of codes which can be identified as cultural, educational, economical, and social. For example, ethnocentric beliefs are habits of intellect where individuals believe there are superior to other groups, and this develops into a personal outlook where, for example, heterosexuals believe they are superior to homosexuals.

The transformative learning theory also suggests that the process of transformation of one's perceptive occurs through three elements - psychological, convictional and behavioral. In transformational learning, the psychological awareness occurs when the learners modify their self-perception, followed by convictional where the learners evaluate and appraise their belief system, and finally, behavioral where they implement the changes in their everyday lives (E. Taylor, 2007). Transformation of structures of references, personal outlook and habits of intellect, in any individuals can be transformed through education and critical contemplation and self-reflection. Therefore, educators in higher education institutions must recognize the importance of transformative learning and the process 
in which transformative learning expands learners view and perception of the changing world and their surroundings (Mezirow, 1991).

According to Weaver (2008), in the current changing world with advancements in technology, today's students' learning approach has changed. Today, students no longer require teacher-centered lectures and the old approach to learning. Students expect higher education institutions to provide them with learning opportunities that support their intellectual and spiritual needs; in other words, they expect universities to help them grow holistically as individuals. Weaver (2008) indicated that university administrators and faculty members must provide students with multidisciplinary knowledge in a student-centered learning environment where students are encouraged to speak, debate, and do activities as groups.

According to Williams (2010), in today's economy, university graduates are expected to change jobs a few times during their career. This is sometimes due to change of interest, but more often due to advancements in technology and developments in their field. In some cases, the field in which the student obtained a degree in develops and changes considerably, leaving the graduate's skills outdated. The University of Central Oklahoma is aware of the changing economy and, through the Center for Transformative Learning, prepares its future graduates in dealing with such obstacles. The university opened the center to teach students valuable life-long skills, such as leadership skills that can enable them to reach out to a larger community. The center adheres to transformative learning theory and places the student in the center of the learning process. Therefore, the students who engage in transformative learning are constant active learners who can respond to obstacles more effectively, and students are taught to continuously evaluate, reflect and develop their skills and their perception on various subjects and the world around them. According to Williams (2010), at the University of Central Oklahoma, all students are required to engage in several transformative learning activities, such as research, leadership, creative thinking, community service, global and cultural appreciation, and health and wellness awareness. The goal of the Transformative Centre is to provide students with the skills so they could adapt in the changing world and the changes that may occur in their career lives. A significant notion of the Transformative Centre is to reduce students' lecture hours and increase the time where they are fully engaged. For example, after a short lecture, students are given the opportunity to engage in discussions or group projects - a more student-centered and interactive learning experience (Marmon, 2010; Williams, 2010).

\section{CHALLENGES FACED BY ACADEMIC LEADERS}

Encouraging higher education institutions to implement interdisciplinary programs, and including contemplative, experiential and transformational learning practices in their curriculum, is often a challenging task faced by many higher education leaders. According to Zajonc (2006), in many institutions there are traditional ways of teaching and following a curriculum - practices that are long-established and deep rooted in the history of the discipline and the institution. Hence, making modifications to these traditional practices is not always favored or well received. However, Zajonc (2006) stated that higher education leaders must encourage faculty members to recognize that an important aspect of liberal education in not merely teaching the theories and methodologies, but also recognizing their boundaries and restrictions and their effects on the students and their lives. According to Zajonc (2006), in today's global community where imperative ethical issues regarding environmental, social, political and economic practices are being examined, educators must ensure to incorporate contemplative, experiential and transformative learning practices in their teaching and class activities. Some instructors distance themselves from teaching contemplative practices as they fear it advocates religious ideologies. However, according to contemplative principles, spiritual and transformational teachings are not necessarily a call for return of religious practices in liberal education. Moreover, they are to provide a different dimension to liberal education where students are taught to look at issues not just critically, but also have a more passionate and sensitive insight on issues, which, in actuality, is rooted in the foundation of liberal education since its establishment (Zajonc, 2006).

Over the past years, there has been a shift in these beliefs in American higher education institutions. Today, more public and private higher education institutions in the United States are reconsidering, including contemplative, transformational, and experiential learning practices in their curriculum. In 2002 the University of Massachusetts at Amherst with collaboration of Wellesley College, sponsored a conference on spirituality and contemplation in higher education, which was well received. Following the conference, an initiative was put in place 
for the American Council of Learned Societies (ACLS) to fund 100 contemplative practice fellowships to faculties from 80 universities who were interested in developing courses dedicated to contemplative practices. Another noteworthy conception has been the development of the Academic Program of the Centre for Contemplative Mind in Society, which supports several programs, including Contemplative Law programs, and is a collaborative project between many law professors from different law schools, such as Yale and Harvard (Zajonc, 2006).

Holley (2009) conducted a research and looked at case studies from 21 higher education institutions in the United States who have been engaged in developing interdisciplinary programs on their campuses in order to promote transformative learning. Holly (2009) found that these attempts can produce significant alteration within the institution's dynamics, and in order for institutions to promote transformational learning through interdisciplinary activities, a strong collaboration between higher administration and faculty and staff members is required. In institutions where collaborative work among various departments and faculty members has been limited, it is more difficult to engage in interdisciplinary activities because each department and faculty member follows a different standard depending on their field, which could create conflict. A major challenge is deciding on a multidisciplinary language because language that has a particular definition in one discipline could have an entirely different definition in another discipline (Holley, 2009). According to Brint, Turk-Bicakei, Proctor, Murphy, and Hanneman (2009), higher education institutions in the United States are working toward creating interdisciplinary educations in order to meet the current market demands. Through incorporation of social issues and global awareness, they can prepare their graduates for the current global economy. Interdisciplinary education is important, specifically since subjects, such as social issues and global awareness, are not perceived as harmonious with other disciplines at hand. Examples of interdisciplinary programs include gender issues, environmental studies, and international health studies. Bess and Dee (2008) argued that interdisciplinary education within an institution does not only affect and transform the students, but it also impacts the members of the institutions in the way they perceive themselves, their profession, and their institution. While institutions' goals have always been to educate, research, and provide service to their community, institutions can accomplish these objectives more efficiently through interdisciplinary education. Holley (2009) indicated that it is important to note that encouraging interdisciplinary collaboration within an institution does not always take place effortlessly and sometimes it fails completely. Interdisciplinary collaboration requires time, dedication and patience while changes occur within the university's structures and disciplines. Since interdisciplinary collaboration requires cooperative work between administration, staff and faculty members, it is essential that everyone who is involved is fully committed to the goal. Senior administrators supply the means required for the change and have an important voice in encouraging collaborative work. Through encouragement and involvement of all the members of the institution, the feeling of ownership toward interdisciplinary collaboration extends to the entire campus community (Holly, 2009). Therefore, for institutions to pursue interdisciplinary collaboration and create interdisciplinary programs, they require not merely a vision, but also visible action plan where they assign individuals, departments, and physical space to this goal. For example, in 1998, Duke University in the United States was the first university to assign a full-time Vice Provost to oversee its interdisciplinary activities and the creation of its Interdisciplinary Studies department, which in 2006 was also assigned its own building (Bess \& Dee, 2008; Holley 2009).

Many faculty members in universities are separated by disciplinary margins, and while it is important to encourage collaborative work among them, Holley (2009) suggested that the most effective way to make interdisciplinary change possible is though employing faculty members who specialize in interdisciplinary studies. For example, in 2002 the University of Southern California initiated a plan to employ 100 faculty members with multidisciplinary backgrounds and expertise. The University president, Steven Sample, explained in a speech that the university's objective is to provide graduates with interdisciplinary education in order to prepare them for the current global issues.

\section{CONCLUSION}

For societies to flourish, they require citizens who are knowledgeable, skilled, and have a thorough understanding of the world they live in. The resolution to creating such citizens lies in the hands of higher education institutions who have the influence to provide learners with educational opportunities that value and offer contemplative, experiential, and transformation learning ideologies. In today's world where a large population struggles with issues such as war, crime, pollution, and poverty, it is critical that higher education institutions 
implement multidimensional educational approaches in their curricula and encourage a more vigorous and universal understanding of cross-cultural communication and social capabilities. For any higher education institution to develop in the direction of excellence, it requires individuals, faculty members, administrators, and leaders who are committed to educational reform and students' success and are willing to overcome challenges and barriers in order to reach their institution's full potential (Palmer \& Zajonc, 2010). Therefore, higher education leaders must encourage their faculty members and staff to overcome variances in order to collaborate and develop multidisciplinary educational programs that will broaden students' understanding of their world. It is hence through such knowledge of the world, appreciation, and mindfulness that students can develop to be valuable citizens and create a better world.

\section{AUTHOR INFORMATION}

Sepideh Mahani is a Communications and Liberal Arts lecturer at the Higher Colleges of Technology in Abu Dhabi, United Arab Emirates. She graduated with a Bachelors degree in Political Science from York University, Canada, a TEFL diploma from the University of Saskatchewan and a Master of Education in Higher Education Leadership from Northcentral University. She is currently a doctoral candidate in the School of Education at the Northcentral University in the United States. Her research interests include minority students, first-generation students, globalization of higher education, andragogy and the role of post-secondary institutions and higher education policy in facilitating access for and the success of women in STEM fields. Presently she is leading the development of an Ethical Studies course for EFL learners at Higher Colleges of Technology. She is a member of Association for the Study of Higher Education (ASHE) and Kappa Delta Pi, international honour society. E-mail: smahani@hct.ac.ae

\section{REFERENCES}

1. Bess, J., \& Dee, J. (2008). Understanding college and university organization: Theories for effective policy and practice. Sterling, VA: Stylus.

2. Brint, S., Turk-Bicakei, L., Proctor, K., Murphy, S., \& Hanneman, R. (2009). The market model and the growth and decline of academic fields in US colleges and universities, 1975-2000. The Journal of Higher Education, 80(1), 605-643. Retrieved from http://www.highered2000.ucr.edu/Publications/Brint\%20et\%20al\%20(2011d).pdf

3. $\quad$ Dewey, J. (1938). Experience and education. New York: 595 Macmillan.

4. Dolan, M. (2011). Connecting thought and action for beginners: A meditation on integral philosophy and experiments in the yoga of love, action, knowledge. Integral Review, 7(1), 62-75. Retrieved from http://www.integralreview.org/documents/Dolan,\%20Vol.\%207,\%20No.\%201,\%20CIIS\%20Special\%20Issue.pdf

5. Holley, K., (2009). Interdisciplinary strategies as transformative change in higher education. Innovative Higher Education, 34(1), 331-344. doi:10.1007/s10755-009-9121-1

6. Kolb D. A, (1984). Experiential learning: experience as the source of learning and development. New Jersey: Prentice-Hall.

7. Marmon, E., L. (2010). Cross-cultural field education: A transformative learning experience. Christian Education Journal, 7(1), 70-84. Retrieved from EBSCOhost

8. Mezirow, J. (1991). Transformative dimensions of adult learning (1st ed.). San Francisco: Jossey-Bass.

9. Palmer, P. J., \& Zajonc, A. (2010). The heart of higher education: A call to renewal. San Francisco, CA: Jossey-Bass.

10. Rathunde, K. (2009). Experiential wisdom and optimal experience: Interviews with three distinguished lifelong learners. Journal of Adult Development, 17(2), 81-93. doi:10.1007/s10804-009-9083-x

11. Sansone, C. (2009). What's interest got to do with it? Potential trade-offs in the self-regulation of motivation. In J. Forgas, R. Baumeister, \& D. Tice (Eds.), Psychology of self-regulation (pp. 36-51). New York, NY: Psychology Press.

12. Sibthorp, J., Schumann, S., Gookin, J., Baynes, S., Paisley, K., Rathunde, K. (2011). Experiential education and lifelong learning: Examining optimal engagement in college students. Journal of Experiential Education, 33(4), 388-392. doi:10.5193/JEE33.4.388 
13. Taylor, E. W. (2007). An update of transformative learning theory: A critical review of the empirical research (1999-2005). International Journal of Lifelong Education, 26(2), 173-191. Retrieved from EBSCOhost

14. Taylor, M. L. (2007). The seven liberal arts: A crown of sonnets. Atlanta Review, 14(1), 58-60. Retrieved from EBSCOhost

15. Weaver M. (2008). Transformative learning support models in higher education: Educating the whole student. Facet Press, London.

16. Williams, J., A. (2010, September 25). UCO's new center teaches thinking beyond a degree. The Oklahoman . Retrieved from EBSCOhost.

17. Wilson, A. (2011). Humanism and integrative education: Enhancing the dialogue on religious Pluralism. The Journal of College Student Development, 37(2), 1-7. Retrieved from http://www2.myacpa.org/spirituality-suggested-readings

18. Zajonc, A., (2006) Love and Knowledge: Recovering the Heart of Learning Through Contemplation," Teachers College Record, vol. 108, no. 9, pp. 1742-1759. 